\title{
Whole-exome sequencing identifies homozygous mutation in TTI2 in a child with primary microcephaly: a case report
}

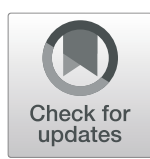

\author{
Vincent Picher-Martel ${ }^{1 *}$ D, Yvan Labrie ${ }^{2}$, Serge Rivest ${ }^{3}$, Baiba Lace ${ }^{4}$ and Nicolas Chrestian ${ }^{5}$
}

\begin{abstract}
Background: Primary microcephaly is defined as reduced occipital-frontal circumference noticeable before 36 weeks of gestation. Large amount of insults might lead to microcephaly including infections, hypoxia and genetic mutations. More than 16 genes are described in autosomal recessive primary microcephaly. However, the cause of microcephaly remains unclear in many cases after extensive investigations and genetic screening.

Case presentation: Here, we described the case of a boy with primary microcephaly who presented to a neurology clinic with short stature, global development delay, dyskinetic movement, strabismus and dysmorphic features. We performed microcephaly investigations and genetic panels. Then, we performed whole-exome sequencing to identify any genetic cause. Microcephaly investigations and genetic panels were negative, but we found a new D317V homozygous mutation in TELOE-2 interacting protein 2 (TT/2) gene by whole-exome sequencing. TT12 is implicated in DNA damage response and mutation in that gene was previously described in mental retardation, autosomal recessive 39.
\end{abstract}

Conclusions: We described the first French Canadian case with primary microcephaly and global developmental delay secondary to a new D317V homozygous mutation in 712 gene. Our report also highlights the importance of TT12 protein in brain development.

Keywords: TT12, Microcephaly, Whole-exome sequencing, Case report

\section{Background}

Microcephaly is generally defined as a significant reduction in occipital-frontal head circumference (OFC). Primary microcephaly could be detectable before 36 weeks of gestation whereas secondary microcephaly is developed after birth. Primary microcephaly could be caused by infections (CMV, toxoplasma, rubella, herpes, HIV), ischemia or hypoxia, exposure to alcohol or drugs, mitochondrial mutations or autosomal recessive mutations [1]. Autosomal recessive primary microcephaly $(\mathrm{MCPH}$; Microcephaly Primary Hereditary) is a rare disorder with incidence around 1 to $8 / 250000$ live births [2]. More than 16 genes have been reported. The cause of

\footnotetext{
* Correspondence: vincent.picher-martel.1@ulaval.ca

'Department of psychiatry and neurosciences, Centre de recherche Cervo Brain Research Centre and CHU de Québec, Laval University, 2601 chemin de la canardière, Québec, Qc G1J 2G3, Canada

Full list of author information is available at the end of the article
}

microcephaly remains unclear in many cases after extensive investigations.

Here, we report a child with primary microcephaly carrying D317V Homozygous mutation in TELO2interacting protein 2 (TTI2) gene, identified by wholeexome sequencing (WES). We described the features associated with the mutation and discussed about TTI2 implication in neurodevelopment. TTI2 protein is implicated in DNA damage response (DDR) and is a part of the TTT complex with telomere length regulation protein TELO2 (Tel2) and TTI1. The TTT chaperone complex interact with Hsp90 to promote stability of the phosphatidylinositol 3-kinase-related kinases (PIKKs) [3-5] implicated in numerous cell functions (Fig. 1a) [10]. A mutation in TTI2 was previously descr

ibed in mental retardation, autosomal recessive 39 in three affected siblings with microcephaly at $30-36$ years of age [6].. Recently, two publications reported cases of compound heterozygous mutations, implying that the

(c) The Author(s). 2020 Open Access This article is distributed under the terms of the Creative Commons Attribution 4.0 International License (http://creativecommons.org/licenses/by/4.0/), which permits unrestricted use, distribution, and 


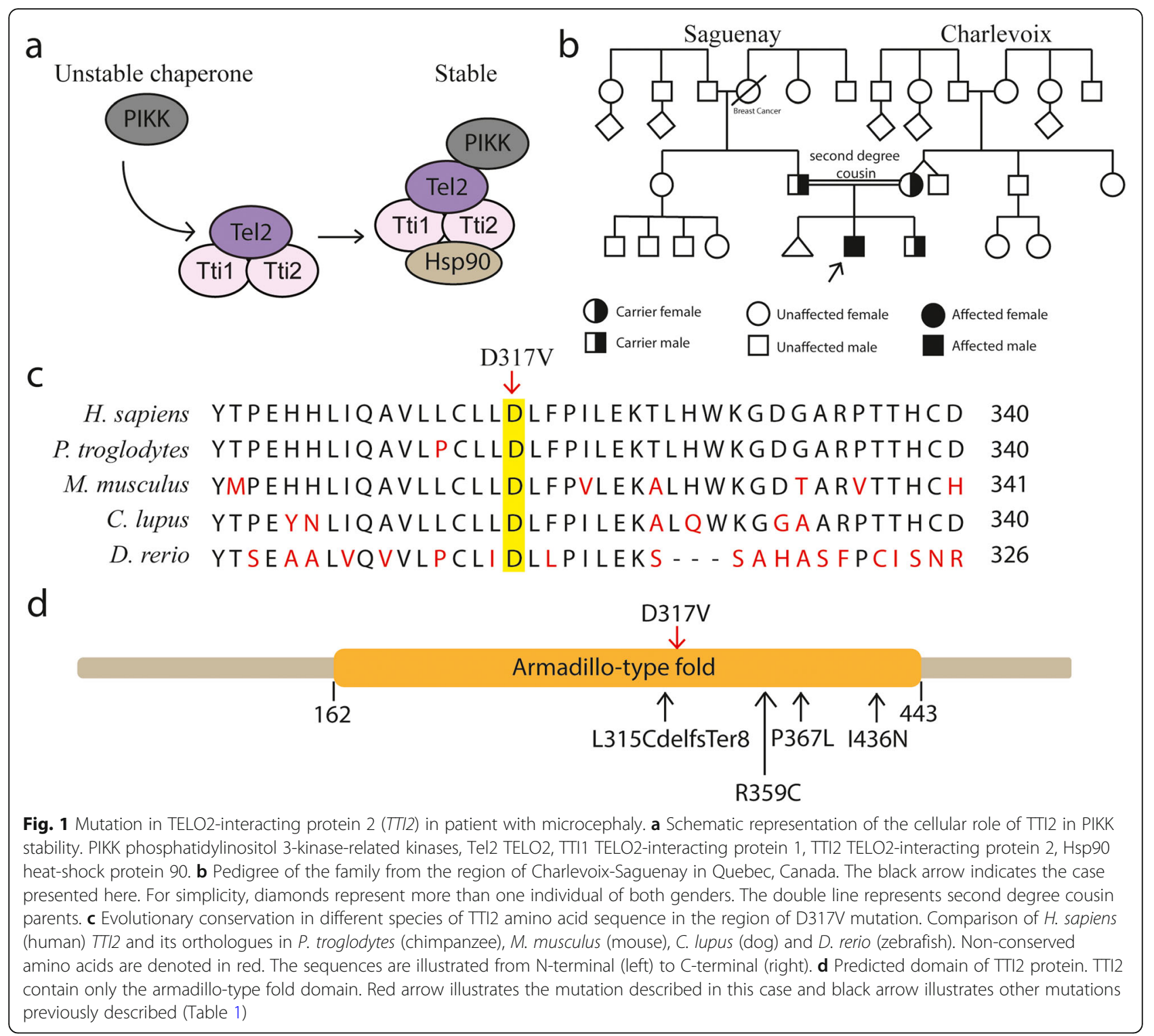

clinical spectrum of TTI2 is evolving [8, 9]. This disorder is characterized by reduced intellectual functioning associated with impairment in adaptative behavior, delayed psychomotor development and short stature. Our patient highlights the importance of TTI2 protein in normal brain development and increases the phenotypic description of TTI2 related microcephaly.

\section{Case presentation}

The patient was originally referred to our neuropediatric clinic at 11 months of age for global development delay and convergent strabismus. The boy was born from healthy second cousin French Canadian parents (Fig. 1b). The pregnancy and delivery were unremarkable except for suspected in utero microcephaly during a prenatal ultrasound at 34 weeks of gestation $(<4$ th percentile). The boy weight $2732 \mathrm{~kg}$ (5th percentile) with $31,5 \mathrm{~cm}$ of OFC ( $<3 \mathrm{rd}$ percentile) and height of $49 \mathrm{~cm}$ (25th percentile) at birth (Fig. 2d-f). At 4 months of age, the parents observed hypotonia, abnormal limb choreiform and athetoid movements and strabismus. At medical evaluation, the child had language retardation with only warbles, global motor retardation, slight axial hypotonia, dyskinesia, mannerism, convergent strabismus, microcephaly with OFC at $40 \mathrm{~cm}$ ( $>2 \mathrm{SD},<2$ nd percentile) as well as normal strength. At 1 year of age, brain imaging by magnetic resonance imaging (MRI) revealed no gross abnormality except mild supratentorial ventriculomegaly and mild to moderate mixed diffuse cortical atrophy (Fig. 2a-c). Electroencephalographic studies revealed no epileptic abnormality with normal background rhythm. At 2 years of age, the child had severe language 


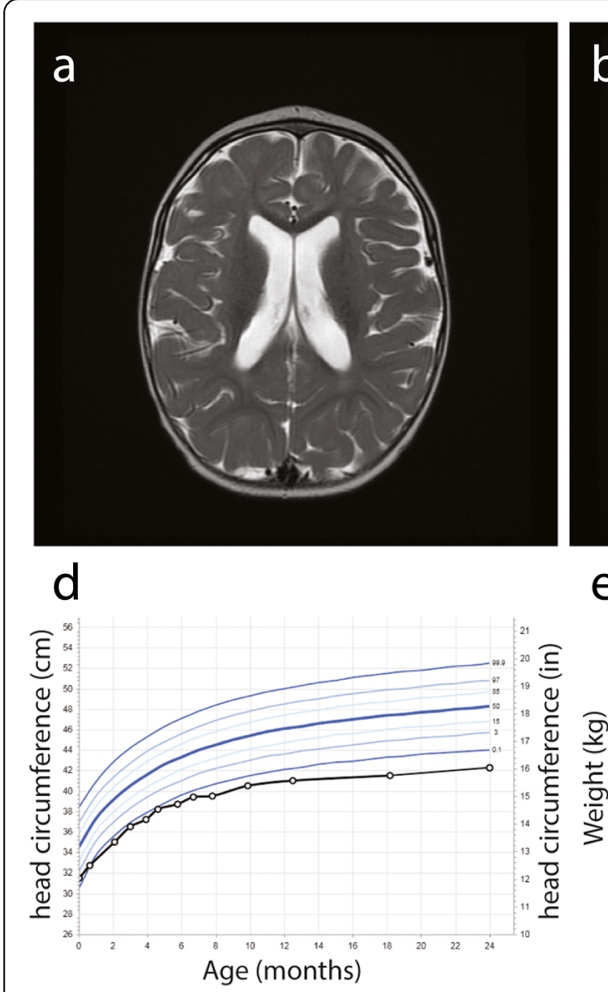

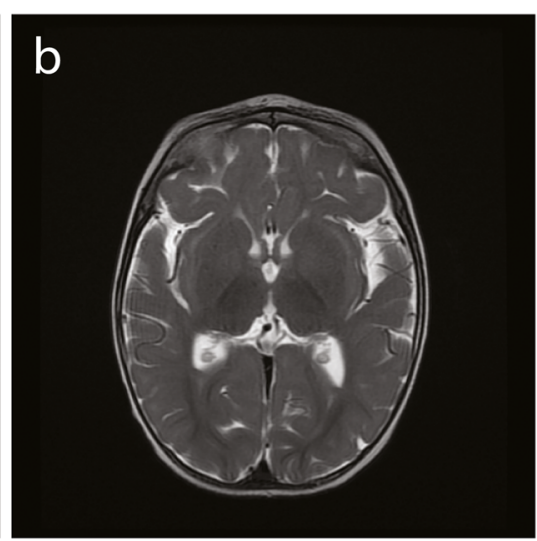

e

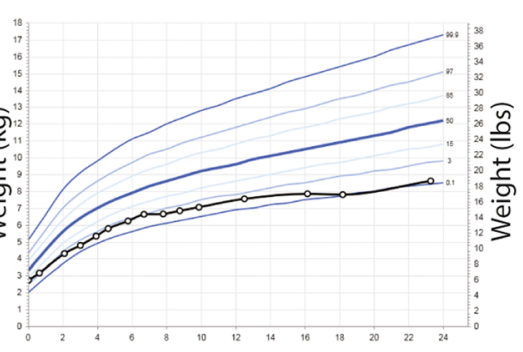

Age (months)

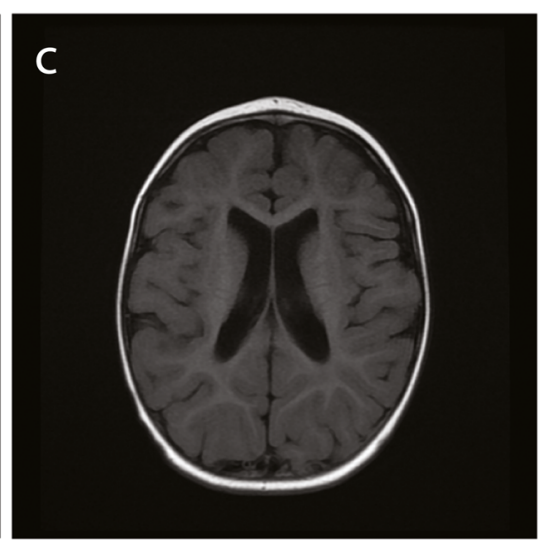

f

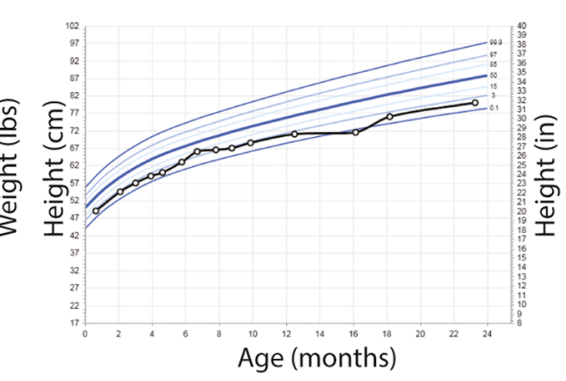

Fig. 2 Clinical phenotype of the patient with $T \pi / 2$ mutation. a-b axial T2 images and $\mathbf{c}$ axial Flair image of brain magnetic resonance imaging (MRI) from the boy at 1 year of age. Small supratentorial ventriculomegaly and minor mixed diffuse cortical atrophy can be observed. $\mathbf{d}$-f Growth curves for head circumference $(\mathbf{d})$, weight (e) and height $(\mathbf{f})$ from birth to the age of two years old. Blue line indicate percentile from age and sex matched controls

dysfunction, severe microcephaly with $\mathrm{OFC}$ at $42.5 \mathrm{~cm}$ $(<0.1$ percentile) and short stature with heighted 78.5 $\mathrm{cm}$ (0.7 percentile) and weighted $9.3 \mathrm{~kg}$ ( 0.1 percentile) (Fig. 2d-f). The patient also exhibits dysmorphic features including fair complexion, narrow and triangular face, forehead with prominent metopic ridge, a deep set of eyes, a high palate and a supernumerary nipple (Fig. 3). At 4 years of age, he was able to follow 2 step simple commands but without any words. He was able to recognize some letters and numbers. His gross motor development was with normal range (walking independently, climbing stairs, jumping, using tricycle) and had mild fine motor skills difficulties. He still presents short stature $81 \mathrm{~cm}(<0.1$ percentile), low weight $12 \mathrm{~kg}(<0.1$ percentile) and severe microcephaly at $43 \mathrm{~cm}(<0.1$ percentile) (Fig. 2).

Large investigations for causes of primary microcephaly were performed. No infectious causes were detected, and the lactate levels were 1.1 to $2.8 \mathrm{mmol} / \mathrm{L}$. The investigations revealed no abnormalities in levels of urinary organic acid, in levels of blood amino acids, in acylcarnitine profile, purines and pyrimidines and sterols profile. Genetic panels were performed before whole-exome sequencing. The nuclear mitochondrial genes panel (Fulgent, Temple City, USA) included 505 genes and revealed variants in five genes. The panel revealed an
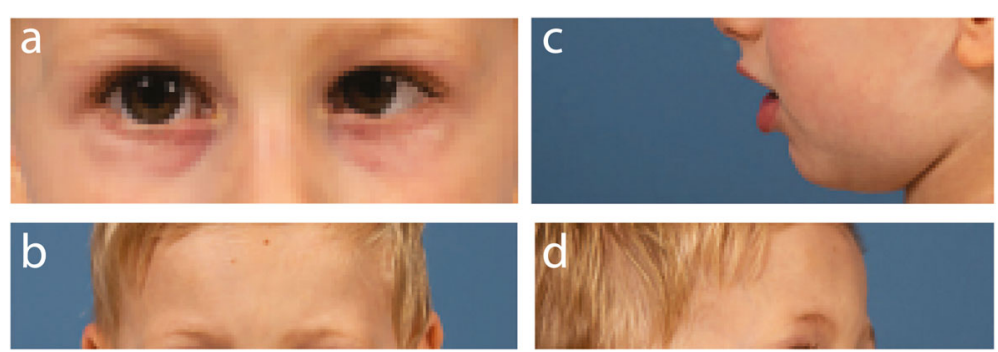

Fig. 3 Patient's phenotypic features. a-d Samples pictures of the described patient 1 month before his fourth birthday. We can denote the strabismus (a), a deep set of eyes (b), a high palate (c) and the forehead with prominent metopic ridge (d) 
heterozygous mutation in CYP2781 which is known to be pathogenic when homozygous. The panel also revealed heterozygous variants of unknown significance in CFTR, RYR1, AKAP10 and SARDH. Detection of Autosomal Recessive Primary Microcephaly Series (ASPM) (University of Chicago, USA) was negative and the autosomal recessive primary microcephaly Tier 2 sequencing and deletion/duplication panel (University of Chicago, USA) revealed autosomal recessive heterozygous variant of unknown significance in CASC5. The Prader-Willi and Angelman's syndrome methylation study performed in our centre was negative (Centre Hospitalier Université Laval, Canada). Finally, no mutation was found in $M E C P 2$ for Rett's syndrome (University of Montreal, CHU de Ste-Justine, Canada).

Whole-exome sequencing was performed at the CRCHU de Québec- UL genomic center (Quebec, Canada) as described in materials and methods (Additional file 1). The WES identified homozygous variant in the TTI2 gene: c.950A > T (p.Asp317Val) (Fig. 1c). The variant was exonic missense. Both parents were heterozygous for this variant and the sibling was an unaffected heterozygous carrier. The D317V homozygous variant in TTI2 was confirmed by independent single gene sequencing (Fulgent, Temple City, USA). The variant was less frequent than $0.01 \%$ in Broad dataset. The aspartate is highly conserved within all mammals and nonmammalian vertebrates, which suggest a primordial role of aspartate in protein structure (Fig. 1c). Indeed, the change from aspartate to valine is radical with a physiochemical difference in Grantham's Distance of 152 [11].

\section{Discussion and conclusions}

In this study, by whole-exome sequencing, we identified the first French Canadian case with autosomal recessive homozygous TTI2 mutation in a child with severe microcephaly, short stature, dyskinesia, convergent strabismus and dysmorphic features. We described the first homozygous c.950A $>\mathrm{T}$ (p.Asp317Val) mutation in TTI2 gene causing primary progressive microcephaly and short stature. During the preparation of this manuscript, two other groups report compounds heterozygous mutations in children with intellectual disabilities and microcephaly (Table 1), but none were homozygous for this mutation $[8,9]$.. Another mutation, c. $1307 \mathrm{~T}>\mathrm{A}$ (p.Ile436Asn), in TTI2 gene was previously described in three siblings born from healthy first cousin parents [6]. Contrary to our case, the siblings had normal neonatal period and developed progressive microcephaly with OCF reaching -3/-4 SD at 30-36 years old. Another missense TTI2 mutation (p.Pro367Leu) was described in a large consanguineous Iranian family with intellectual disability [7]. The defined homozygous mutation in our case probably come from a strong founder effect found in the French Canadian from the region of CharlevoixSaguenay, Quebec [12]. The phenotype is similar in all cases and the most frequent findings include primary or progressive microcephaly $(80 \%)$, dysmorphic features (80\%), severe cognitive impairment (70\%), severe speech delay (70\%), strabismus (70\%), movement disorder $(60 \%)$, short stature $(60 \%)$ and scoliosis $(50 \%)$ (Table 1$)$.

Our study and the review of the literature suggested an important role for TTI2 in brain development. It is noteworthy that all identified mutations are located in the Armadillo-type fold domain of TTI2 (Fig. 1d). The superhelical structures of the Armadillo-type fold domain is necessary for binding to its large substrates including other members of the TTT complex [13]. TTI2 plays a key role in promoting the stability of the PIKK family. The PIKK family include DNA-PK, ATM, ATR,

Table 1 Summary of genetic variance in TT/2 gene

\begin{tabular}{|c|c|c|c|c|}
\hline CDNA & $\begin{array}{l}\text { Amino acid changes } \\
\text { (Abbreviated) }\end{array}$ & $\begin{array}{l}\text { Number } \\
\text { of cases }\end{array}$ & Clinical characteristics & References \\
\hline c. $1307 \mathrm{~T}>\mathrm{A}$ & p.lle436Asn (1436N) & 3 & $\begin{array}{l}\text { Normal Growth parameters, microcephaly at adult age, severe } \\
\text { cognitive impairment, severe speech delay, short stature, } \\
\text { dysmorphic features, vertebral anomalies }\end{array}$ & {$[6]$} \\
\hline c. $1100 C>T$ & p.Pro367Leu (P367L) & 2 & Non-syndromic moderate intellectual disability & {$[7]$} \\
\hline c.950A > T & p.Asp317Val (D317V) & 1 & $\begin{array}{l}\text { Primary microcephaly, short stature, severe speech delay, } \\
\text { dysmorphic features, strabismus, dyskinesia }\end{array}$ & $\begin{array}{l}\text { Described } \\
\text { here }\end{array}$ \\
\hline $\begin{array}{l}\text { Patient } 1 \text { compound } \\
\text { c. } 1075 \mathrm{C}>\mathrm{T} \text { and } \\
\text { c.950A }>\mathrm{T} \\
\text { and } \\
\text { Patient } 2 \text { compound } \\
\text { c.539 T }>\text { C and c.575 } \\
\text { T }>\text { C }\end{array}$ & $\begin{array}{l}\text { p.Arg359Cys and p.Asp317Val } \\
\text { (R359C and D317V) } \\
\text { p.Leu180Pro and p.Leu192Pro } \\
\text { (L180P and L192P) }\end{array}$ & 2 & $\begin{array}{l}\text { Intellectual disabilities, progressive microcephaly, high nasal bridge, } \\
\text { deep-set eyes, partial ovarian failure }\end{array}$ & {$[8]$} \\
\hline $\begin{array}{l}{ }^{\mathrm{a}} \text { Compound C.942_- } \\
\text { 944delTCTins and } \\
\text { C. } 1100 \mathrm{C}>\mathrm{T}\end{array}$ & $\begin{array}{l}\text { p.Leu315CysfsTer8 and } \\
\text { p.Pro367Leu (L315CdelfsTer8 } \\
\text { and P367L) }\end{array}$ & 2 & $\begin{array}{l}\text { Intellectual disabilities, microcephaly, growth retardation, speech } \\
\text { disorder, movement disorders }\end{array}$ & {$[9]$} \\
\hline
\end{tabular}

${ }^{a}$ Complete mutation name c.942_944delTCTinsCTGTGCTTCCATTCCTCCTCCTAG 
MTOR, SMG-1 and TRRAP. DNA-PK, ATM and ATR are implicated in cellular response to double-strand DNA break [14]. MTOR is implicated in metabolism, cell growth, autophagy and in maintenance of cytoskeleton [15], whereas SMG-1 is more implicated in surveillance of non-sense mRNA to prevent translation of truncated protein $[16,17]$. TRRAP do not possess any kinase activity but is implicated in chromatin maintenance [18]. Patients with mutation in TTI2 exhibited decreased level and activity of all PIKK members by dysfunction of the TTI1- TTI2-TELO2 complex [6]. It is not clear how deficits in PIKK proteins can cause neurodevelopmental defect. However, studies in animal models of MCPH have revealed important role of DNA damage response in embryonic neurogenesis [19-21]. By example, premature neurogenesis leading to a reduction in the number of neuronal cells was caused by a ventricular neural stem cell defect in MCPH models [2224]. Mutations in TELO2 gene also caused PIKKs dysfunction and severe intellectual disability associated with microcephaly, visual and hearing impairments and abnormal movements [25].

There are numerous genes implicated in DNA reparation. Mutations in those genes can lead to pathology with similar landscapes. This include Nijmegen Breakage syndrome, ataxia-telangiectasia, DNA-ligase IV deficiency, seckel syndrome 1, Cernunnos-XLF and bloom syndrome. These syndromes generally have a combination of microcephaly, intellectual disability, short stature, skeletal abnormalities and facial dysmorphisms. The same features were observed in our patient, except for the presence of skeletal abnormalities. One of the PIKKs proteins, mTOR, is particularly implicated in dendritic translation which have important impact on spine morphogenesis and synaptic plasticity [26, 27]. Indeed, mTOR dysregulation could lead to cognitive deficits [28].

In conclusions, we described the first French Canadian case with primary microcephaly and global developmental delay secondary to a new D317V homozygous mutation in TTI2 gene. This finding associated with other findings suggested an important role for the TTT complex in brain development. Our findings enlarge the phenotypic variability observed with TTI2 mutations showing that TTI2 related microcephaly could present with less disability than previously described. Though, TTI2 should be included in any microcephaly panel to reach an accurate genetic diagnosis.

\section{Supplementary information}

Supplementary information accompanies this paper at https://doi.org/10. 1186/s12883-020-01643-1.

Additional file 1. Materials and methods. Methods for exome sequencing analysis including DNA extraction and cell line immortalization, library preparation, whole exome sequencing, bioinformatic analyses of exome data, variant filtering and sanger sequencing.

\section{Abbreviations}

Hsp90: Heat-shock protein 90; MCPH: Microcephaly primary hereditary; OFC: Occipital-frontal head circumference; PIKKs: Phosphatidylinositol 3kinase-related kinases; TTI2: TELO2-interacting protein 2; WES: Whole-exome sequencing

\section{Acknowledgements}

We wish to thank the family reported here for their willingness to participate in these research efforts. The authors wish to acknowledge the contribution of the high-throughput sequencing platform and Bioinformatic platform of the Centre de recherche du CHU de Québec-Université Laval, Québec, Canada and Louise Lapointe et Nadie Rioux, the research nurses of the project.

\section{Authors' contributions}

VP-M wrote the case report and prepared the figures and the Table. NC and $\mathrm{BL}$ investigated and followed the patient, designed the study and substantively revised the manuscript. $\mathrm{YL}$ and SR performed the whole-exome sequencing. All authors have read and approved the manuscript.

\section{Funding}

V.P-M held a Frederick Banting and Charles Best doctoral scholarship from Canadian Institutes of Health Research $(\mathrm{CIHR})$ during the preparation of this manuscript. This study also received funding from Fondation Marcelle et Jean Coutu, Fondation du CHU de Québec, Fondation des Étoiles and Fondation Sandra et Alain Bouchard. Financial help was received for wholeexome sequencing, but the funding sources had no role in any step of the study design nor manuscript preparation and submission.

\section{Availability of data and materials}

The datasets used and/or analysed during the current study are available from the corresponding author on reasonable request. Anonymized data will be shared by request from any qualified investigator.

Ethics approval and consent to participate

The institutional review board from Laval University approved this project.

Consent for publication

Written consent to publish was obtained from the patient's parents.

\section{Competing interests}

The authors declare that they have no competing interests.

\section{Author details}

${ }^{1}$ Department of psychiatry and neurosciences, Centre de recherche Cervo Brain Research Centre and CHU de Québec, Laval University, 2601 chemin de la canardière, Québec, Qc G1J 2G3, Canada. ${ }^{2}$ Centre de recherche du CHU de Québec-Universtié Laval, Québec, Qc, Canada. ${ }^{3}$ Centre de recherche CHU de Québec- Universtié Laval, Québec, Qc, Canada. ${ }^{4}$ Department of Clinical Genetic, CHU de Québec- Université Laval, Québec, Qc, Canada.

${ }^{5}$ Department of Paediatric Neurology, Paediatric Neuromuscular Disorder, Centre Mère Enfant Soleil, Laval University, Québec, Qc, Canada.

Received: 23 December 2019 Accepted: 12 February 2020

Published online: 15 February 2020

References

1. Woods CG, Parker A. Investigating microcephaly. Arch Dis Child. 2013;98(9): 707-13.

2. Van Den Bosch J. Microcephaly in the Netherlands: a clinical and genetical study. Ann Hum Genet. 1959:23(2):91-116.

3. Takai $H$, Wang RC, Takai KK, Yang $H$, de Lange $T$. Tel2 regulates the stability of PI3K-related protein kinases. Cell. 2007;131(7):1248-59.

4. Kanoh J, Yanagida M. Tel2: a common partner of PIK-related kinases and a link between DNA checkpoint and nutritional response? Genes Cells. 2007; 12(12):1301-4. 
5. Sugimoto K. Branching the Tel2 pathway for exact fit on phosphatidylinositol 3-kinase-related kinases. Curr Genet. 2018;64(5):965-70

6. Langouet M, Saadi A, Rieunier G, Moutton S, Siquier-Pernet K, Fernet M, et al. Mutation in $T$ TI2 reveals a role for triple T complex in human brain development. Hum Mutat. 2013;34(11):1472-6.

7. Najmabadi H, Hu H, Garshasbi M, Zemojtel T, Abedini SS, Chen W, et al. Deep sequencing reveals 50 novel genes for recessive cognitive disorders. Nature. 2011;478(7367):57-63.

8. Ziegler A, Bader P, McWalter K, Douglas G, Houdayer C, Bris C, et al. Confirmation that variants in $T T 12$ are responsible for autosomal recessive intellectual disability. Clin Genet. 2019;96(4):354-8.

9. Wang R, Han S, Liu H, Khan A, Xiaerbati H, Yu X, et al. Novel compound heterozygous mutations in $T T / 2$ cause Syndromic intellectual disability in a Chinese family. Front Genet. 2019;10:1060.

10. Blackford AN, Jackson SP. ATM, ATR, and DNA-PK: the trinity at the heart of the DNA damage response. Mol Cell. 2017;66(6):801-17.

11. Grantham R. Amino acid difference formula to help explain protein evolution. Science. 1974;185(4154):862-4.

12. Laberge AM, Michaud J, Richter A, Lemyre E, Lambert M, Brais B, et al. Population history and its impact on medical genetics in Quebec. Clin Genet. 2005;68(4):287-301.

13. Groves MR, Barford D. Topological characteristics of helical repeat proteins. Curr Opin Struct Biol. 1999;9(3):383-9.

14. Shiloh Y. ATM and related protein kinases: safeguarding genome integrity. Nat Rev Cancer. 2003;3(3):155-68.

15. Conciatori F, Bazzichetto C, Falcone I, Pilotto S, Bria E, Cognetti F, et al. Role of mTOR Signaling in Tumor Microenvironment: An Overview. Int J Mol Sci. 2018;19(8):E2453.

16. Yamashita A. Role of SMG-1-mediated Upf1 phosphorylation in mammalian nonsense-mediated mRNA decay. Genes Cells. 2013;18(3):161-75.

17. Long AA, Mahapatra CT, Woodruff EA 3rd, Rohrbough J, Leung HT, Shino S, et al. The nonsense-mediated decay pathway maintains synapse architecture and synaptic vesicle cycle efficacy. J Cell Sci. 2010;123(Pt 19): 3303-15.

18. Murr R, Vaissiere T, Sawan C, Shukla V, Herceg Z. Orchestration of chromatin-based processes: mind the TRRAP. Oncogene. 2007;26(37):535872.

19. Kraemer N, Ravindran E, Zaqout S, Neubert G, Schindler D, Ninnemann O, et al. Loss of CDK5RAP2 affects neural but not non-neural mESC differentiation into cardiomyocytes. Cell Cycle. 2015;14(13):2044-57.

20. Venkatesh $\mathrm{T}$, Suresh PS. Emerging roles of $\mathrm{MCPH1}$ : expedition from primary microcephaly to cancer. Eur J Cell Biol. 2014;93(3):98-105.

21. Gilbert SL, Dobyns WB, Lahn BT. Genetic links between brain development and brain evolution. Nat Rev Genet. 2005:6(7):581-90.

22. Lizarraga SB, Margossian SP, Harris MH, Campagna DR, Han AP, Blevins S, et al. Cdk5rap2 regulates centrosome function and chromosome segregation in neuronal progenitors. Development. 2010;137(11):1907-17.

23. Buchman JJ, Tseng HC, Zhou Y, Frank CL, Xie Z, Tsai LH. Cdk5rap2 interacts with pericentrin to maintain the neural progenitor pool in the developing neocortex. Neuron. 2010:66(3):386-402.

24. Pulvers JN, Bryk J, Fish JL, Wilsch-Brauninger M, Arai Y, Schreier D, et al. Mutations in mouse Aspm (abnormal spindle-like microcephaly associated) cause not only microcephaly but also major defects in the germline. Proc Natl Acad Sci U S A. 2010;107(38):16595-600.

25. You J, Sobreira NL, Gable DL, Jurgens J, Grange DK, Belnap N, et al. A Syndromic intellectual disability disorder caused by variants in TELO2, a gene encoding a component of the TाT complex. Am J Hum Genet. 2016; 98(5):909-18.

26. Campbell DS, Holt CE. Chemotropic responses of retinal growth cones mediated by rapid local protein synthesis and degradation. Neuron. 2001; 32(6):1013-26.

27. Jaworkki J, Spangler S, Seeburg DP, Hoogenraad CC, Sheng M. Control of dendritic arborization by the phosphoinositide-3'-kinase-Akt-mammalian target of rapamycin pathway. J Neurosci. 2005;25(49):11300-12.

28. Ricciardi S, Boggio EM, Grosso S, Lonetti G, Forlani G, Stefanelli G, et al. Reduced AKT/mTOR signaling and protein synthesis dysregulation in a Rett syndrome animal model. Hum Mol Genet. 2011;20(6):1182-96.

\section{Publisher's Note}

Springer Nature remains neutral with regard to jurisdictional claims in published maps and institutional affiliations.

Ready to submit your research? Choose BMC and benefit from:

- fast, convenient online submission

- thorough peer review by experienced researchers in your field

- rapid publication on acceptance

- support for research data, including large and complex data types

- gold Open Access which fosters wider collaboration and increased citations

- maximum visibility for your research: over $100 \mathrm{M}$ website views per year

At $\mathrm{BMC}$, research is always in progress.

Learn more biomedcentral.com/submissions 